\title{
The Stockholm Paradigm: Climate Change and Emerging Disease
}

\author{
Book by D. R. Brooks, Eric P. Hoberg, and Walter A Boeger \\ University of Chicago Press, 2019, 400 pp.
}

Book Review by Dr. Jennifer Bender ${ }^{1}$, Tuskegee University

In light of the Coronavirus of 2020, there could not be a more appropriate time for this book. This text has a specific timeliness that cannot be ignored. As the authors note, "The entire range of species upon which humanity depends for socioeconomic reasons is affected" (p. 14). While we see the world around us fleeing from our own schools because of a pandemic virus, these authors explain how climate change encourages is devastating to the economy and to our bodies. The authors state that it could be the smallest product we consume to the larger population which surrounds us that can be an influence on our health and wellbeing. They also make the point that we are essentially dangerous to each other. 
In light of the Coronavirus of 2020, there could not be a more appropriate time for this book. This text has a specific timeliness that cannot be ignored. As the authors note, "The entire range of species upon which humanity depends for socioeconomic reasons is affected" (p. 14). While we see the world around us fleeing from our own schools because of a pandemic virus, these authors explain how climate change encourages is devastating to the economy and to our bodies. The authors state that it could be the smallest product we consume to the larger population which surrounds us that can be an influence on our health and well-being. They also make the point that we are essentially dangerous to each other.

The authors present a thorough review of the climate change timeline. Not only is it comprehensive in nature, it is an informative and succinct ideology about the world we have been living in. The authors advance the ideas of climate change leading to conflict (p. 19), and how diseases are a national security issue. The fear-mongering section in Chapter One is of particular interest to anyone who would want to know more about the psychology behind diseases, and how we control [and advertise] the problems associated with disease.

Although the rhetoric certainly is entertaining, the authors clearly understand the importance of security and conflict surrounding the pathos of our diseases and epidemics. The author's warnings to us are clear and competent: the authors even mention that they are making "provocative statements" when discussing the fear behind the spread of illnesses (p.23). The authors are strident in their passion for making sure that, we know we are unprepared for the detrimental effects of climate change and illness.

The informative history of this work is substantial, and makes the book worth reading. Not only does the prose of the text speak to the reader, the writing is remarkably engaging and informative. It is a concise and compelling approach to the problems we face today in terms of our resistance and susceptibility to disease.

Brooks, Hoberg, and Boeger note that, "By now it should be clear that we are playing a losing game with respect to dealing with disease" (p. 77). They discuss the role evolution plays in the ways organisms procreate and change, and the dangers we are encountering because of mutations. Throughout the text, a succinct writing style that is productive for the reader. At the end of each chapter, the authors provide an instructive summary, which makes it comfortable for readers to understand the technical aspects of the chapter.

The authors argue that we, as humans, need to learn more about survival, instead of taking risks by studying loss. The authors provide insight on moving forward with how we approach illness, which is incredibly refreshing. Not only do these authors provide the problem behind current epidemics, they also explain how they take place, and where we should go from here.

Although it is a lengthy volume, the in - depth examination into epidemics is covered with a view to the future. This is a fitting text for anyone in the sciences, and may be of particular interest to the medical professionals, as well. As an insightful read, The Stockholm Paradigm encourages us across the disciplines to deliberate on the effects of our behaviors on our Earthly home. 